\title{
Snake bite in pregnancy-case report and review of literature
}

\begin{abstract}
Snake bite affects around 2.5 million annually, with greater than 100,000 deaths. India is known to have one of the highest rates of snake bites in the world. However, reports of venomous snake bites during pregnancy are uncommon, as women in our country are usually homebound during their pregnancy. Little is known about the maternal and fetal outcome following venomous snake bite of a pregnant woman. This case report presents a multigravida who was bitten by a snake at 28 weeks of pregnancy. She developed DIC and abruption placenta and delivered a still born baby. The purpose of this case report is to emphasis on the fact that though the consequences of a snake bite is grave for the fetus and mother, timely and effective medical care can go a long way in saving their lives.
\end{abstract}

Keywords: snake bite, dic, pregnancy, abruption placenta, intra-uterine demise
Volume 2 Issue I - 2017

\author{
Anita David, Padmaja \\ Department of Obstetrics \& Gynecology, Bangalore Baptist \\ Hospital, India
}

\begin{abstract}
Correspondence: Anita David, Obstetrics \& Gynecology Bangalore Baptist Hospital, Karnataka, India, Tel 9901757775 , Email anitawd@gmail.com
\end{abstract}

Received: January 31, 2017 | Published: March 06, 2017

\section{Introduction}

Snake bites are not very commonly seen in pregnancy but they do tend to occur in tropical countries like ours especially in summer. Only few such cases have been reported in literature so far and the outcomes may be different both for the mother and the fetus.

The challenge in this scenario is the serious consequence to the mother in terms of coagulopathy and shock. The fetus is at grave risk of hypoxia and demise. There is also a mention of fetal anomalies and the anaphylactic reaction of the anti-snake venom serum.

The main purpose of this case review is to discuss a rare scenario of a snake bite to a pregnant lady and its clinical presentation. The mother and the fetus need close surveillance and effective treatment. The patient reported here was given $300 \mathrm{ml}$ of anti-snake venom antiserum and blood products in view of her hemolysis and coagulopathy due to snake bite. Despite close monitoring she developed abruption and intrauterine fetal demise. The grave prognosis to the mother and the fetus needs emphasis and awareness.

\section{Case presentation}

A 38 year old, gravid 5 Para 2 living 2 abortion 2, at 7months of amenorrhea, presented with history of snake bite over her right hand. She was admitted in the hospital three hours later. On admission, she was conscious and oriented. She was found to have pallor but her vitals were stable. There was in duration and erythema with fang marks on the right forearm. Systemic examination was normal. On abdominal examination, her uterus was noted to be 28 weeks with no contractions and a regular fetal heart rate.

Management she was treated with polyvalent anti-snake venom which is available as lyophilised equine immunoglobulin's and reconstituted in $10 \mathrm{ml}$ of sterile water. A test dose of $0.1 \mathrm{ml}$ was given intradermally and observed for any anaphylactic reactions for 30 minutes. She was then administered an initial dose of $200 \mathrm{ml}$ slow intravenous, at the rate of $2 \mathrm{ml}$ per minute. This was followed by another $100 \mathrm{ml}$ after 4 hours for the erythema to settle. Her vitals and fetal heart rate were monitored regularly. 17hours later, she complained of sudden abdominal pain and bleeding per vagina. Her uterus was tense and tender. Fetal heart could not be localized and intrauterine fetal demise was confirmed by scan. She expelled a fresh still born baby of $770 \mathrm{~g}$ with retro placental clots.

She was found to have moderate anemia with low platelets and an abnormal coagulation profile. She developed DIC by then which was corrected with blood products. After about 30 vials of anti-snake venom and 4 FFP and 2packed cells and potassium correction her condition became stable. Her investigations became normal and she was discharged after 5 days of hospitalization.

\section{Discussion}

In the past mortality from venomous snake bite was around $25 \%$. The mortality rates are less than $0.5 \%$ now, due to the availability of antivenom and advances in emergency and critical care. ${ }^{1}$ Most species of snakes are not venomous. The factors that affect the clinical manifestation are the species and size of the snake, the age and size of the victim, the time elapsed since the bite and characteristics of the bite location, depth, and number, the amount of venom injected. Hence the severity of poisoning following snakebite varies.

Snake venom is a complex enzyme mixture that can lead to local tissue injury, systemic vascular damage, hemolysis, fibrinolysis and neuromuscular dysfunction. This ultimately leads to failure of various systems. Some species of snakes produce venom that contains enzymes that alter vascular permeability and cause hematological symptoms. There are other species which produce venom with enzymes that block neuromuscular transmission and cause ptosis, respiratory paralysis and other neurological manifestation.

The stress of a snake bite may lead to abortion but it cannot cause DIC and abruption. This snake bite caused hemolysis and coagulopathy which led to abruption and fetal loss. The mother required blood products to stabilize her condition.

\section{Clinical features}

The cardinal signs are the fang marks over the bitten area, localized pain and erythema, progressive edema. ${ }^{2}$ Other symptoms 
and signs are nausea and vomiting, weakness, oral numbness or tingling of tongue and mouth, tachycardia, dizziness, hematemesis, hematuria, thrombocytopenia, and fasciculation's. The local swelling may become apparent within a few minutes to several hours. It may remain localized or in severe cases progress to involve a whole limb. Edema near an airway or involving respiratory muscular block may lead to death.

\section{Fetal outcome}

Several mechanisms have been proposed to explain fetal deaths or abortions after snakebite including fetal anoxia associated with maternal shock after envenomation, direct effect of the venom on the fetus, hemorrhages into the placenta and uterine wall causing abruptio placenta, premature uterine contractions initiated by the venom, pyrexia and cytokine release after tissue damage, maternal hemorrhage with acute fetal anemia causing in utero fetal death, supine hypotension syndrome, and potential maternal anaphylaxis to antivenom. ${ }^{3-8}$

Certain malformations have also been noted after a snake bite. For example, a woman who was bitten by a Russell's viper in her 16th week of pregnancy delivered a baby with hydrocephalus and polydactyl. ${ }^{9}$ Malz reported a woman bitten by a viper in her 12th week who later delivered a baby with multiple anomalies with hydrocephalus. ${ }^{10}$ Though the cause-effect relationship between envenomation and malformations in these 3 cases is unknown, it is possible that snake venom can cause embryo toxic and teratogenic effects. Animal studies have shown snake envenomation to cause anomalies like cleft palate, facial deformities, hepatic and myocardial damage, embryonic deaths and fetal resorption during early organogenesis. ${ }^{11-13}$

\section{Review of literature}

Venomous snakes are classified as elapids (cobras), viperidae (vipers) and colubrids (tree snakes). It has recently been suggested that all snakes may be venomous to a certain degree, with harmless snakes having weak venom and no fangs. ${ }^{14}$ Most snakes currently labeled "nonvenomous" would still be considered harmless according to this theory, as they either lack a venom delivery method or are incapable of delivering enough to endanger a human.

Although the snake bite is a rare event in urban India, it is very common in the rural parts of the country due to its hot climate and agricultural status of the individuals. Most fatalities occur in developing countries where venomous snakes are plentiful, human populations are dense and rapid transport and intensive medical treatment facilities are lacking. In studies from South Africa, India, and Sri Lanka, pregnant women have accounted for $0.4 \%$ to $1.8 \%$ of hospitalized snakebite victims. ${ }^{9}$

From a review of the limited literature, abortions and deaths in fetuses/infants after a mother has been bitten by a venomous snake are not unusual.

Seneviratne et al. ${ }^{10}$ reported that nearly $30 \%$ of the envenomated pregnant mothers had a spontaneous abortion. Malz et al. ${ }^{11}$ reported that 3 of $14(21 \%)$ snakebites resulted in abortion or infant death. Dunnihoo et al. ${ }^{15}$ noted that of 30 reports with some detailed information available, 6 spontaneous abortions, 7 fetal deaths, and 1 elective abortion occurred, a $43 \%$ fetal loss occurrence (excluding the elective abortion). Reid et al. ${ }^{16}$ reported 1 of $5(20 \%)$ women aborted after venomous bite. Dao et al. ${ }^{17}$ reported 4 snakebites in pregnant women leading to fetal death or abortion in 3 of them. One mother was in her fifth month of pregnancy and aborted 2days later, and another was at term when snakebite resulted in death of the fetus.

Most fetal deaths and adverse outcomes were noted with bites of rattlesnakes and Russell's viper. However the time taken to diagnose and treat the patient may have a more significant impact on the outcome when compared to the species of the snake. The interesting side of this case was the pregnancy of the woman. It was a challenging case because there was a 28 -week fetus whose life was probably in danger due to the venom. The other factor that had to be considered was the probable risk secondary to antiserum-related complications. ${ }^{18}$

Antivenoms, which may be used in the treatment of the envenomed expectant mother, can cause anaphylactic reactions that may have an adverse effect on the mother or fetus. The fetal death rate has been reported to be up to $55 \%$ to $58 \%$ in mothers given antivenom. ${ }^{19}$

Though there are very few cases reported in literature of snake bites in pregnancy and its consequences, most authors have reported that antivenom administration has been recommended for reptile bite during pregnancy. ${ }^{20}$ While the safety of antivenom in pregnancy is unclear, the risks of withholding likely outweigh the risks of administering in correct clinical scenarios. If the mother develops an acute anaphylactic reaction to the antivenom, ephedrine or phenylephrine may be given. These drugs are preferred over epinephrine as the latter may adversely affect placental blood flow. ${ }^{21}$

In India, polyvalent antisnake venom is available as a $10 \mathrm{ml}$ vial with lyophilized powder for reconstitution. One $\mathrm{ml}$ of this antiserum can neutralize a certain amount of venom namely $0.6 \mathrm{mg}$ of Cobra venom, $0.6 \mathrm{mg}$ of Russell's viper, $0.45 \mathrm{mg}$ of Common Krait and $0.45 \mathrm{mg}$ of Saw-scaled viper. The dose is titrated depending on the normalization of clinical and laboratory findings. ${ }^{22-25}$

According to literature, antivenom is the most effective treatment but many of these cases can develop hematological as well as obstetrical complications. Unless there is awareness among obstetricians, timely and effective management in these cases may be difficult.

\section{Conclusion}

Snake bite in pregnancy, though rare condition needs awareness as it is a very challenging case to manage. The lives of both the mother and fetus are in danger. Prompt treatment with antivenom and adequate blood products is vital in saving the mother. Timely delivery of the fetus needs to be considered as well.

Envenomations during pregnancy should be reported so that additional information on medical management and fetal outcomes can be evaluated. More animal studies and human investigations are needed to evaluate the effect of snake antivenom on pregnant mothers, embryos, and fetuses.

\section{Acknowledgements}

None.

\section{Conflict of interest}

Author declares that there is no conflict of interest.

\section{References}

1. Duru M, Helvaci MR, Peker E, et al. Human \& Experimental Toxicology. 2008;27(12):931-932. 
2. Pierini SV, Warrell DA, De Paulo A, et al. High incidence of bites and stings by snakes and other animals among rubber tappers and Amazonian Indians of the Jurua Valley, Acre State, Brazil. Toxicon. 1996;34(2):225-267.

3. Pantanowitz L, Guidozzi F. Management of snake and spider. Obstet Gynecol Surv. 1996;51(10):615-620.

4. Bryan G, Nicolas V, Janette AN, et al. Early evolution of the venom system in lizards and snakes. Nature (Letters). 2006;439:584-588.

5. Dao B, Da E, Koalaga AF, et al. Snake bite during pregnancy. Med Trop (Mars). 1997;57(1):100-101.

6. Parrish HM, Khan MS. Snakebite during pregnancy. Report of four cases. Obstet Gynecol. 1966;27(4):468-471.

7.Entman SS, Moise JJ. Anaphylaxis in pregnancy. South Med J. 1984;77(3):402.

8. Sutherland SK, Duncan AW, Tibballs J. Death from a snake bite associated with the supine hypotensive syndrome of pregnancy. Med J Aust. 1982;2(5):238-239.

9.Zugaib M, De Barros AC, Bittar RE, et al. Abruptio placentae following snake bite. Am J Obstet Gynecol.1985;151(6):754-755.

10. Seneviratne SL, De Silva CE, Fonseka MM, et al. Envenoming due to snake bite during pregnancy. Trans R Soc Trop Med Hyg. 2002;96(3):272-274.

11. Malz S. Snake-bite in pregnancy. J Obstet Gynaecol Br Commonw. 1967;74(6):935-937.

12. Gabriel-Robez O, Clavert J. Teratogenic and lethal properties of the various fractions of venom of the viper, Vipera aspis. Acta Anat (Basel).1980;108:226-229.

13. Mohamed AH, Nawar NN, Hanna MM. Some effects of Naja nigricollis envenomation on developing fetal tissue. Toxicon. 1974;12(5):477-480.
14. Penn GB, Ross JW, Ashford A. The effects of arvin on pregnancy in the mouse and the rabbit. Toxicol Appl Pharmacol. 20(4):460-473.

15. Dunnihoo DR, Rush BM, Wise RB, et al. Snake bite poisoning in pregnancy. A review of the literature. J Reprod Med. 1992;37(7):653-658.

16. Reid HA, Chan KE, Thean PC. Prolonged coagulation defect (defibrination syndrome) in Malayan viper bite. Lancet. 1963;1(7282):621-626.

17. Dao B, Da E, Koalaga AP, et al. Snake bite during pregnancy. Med Trop (Mars). 1997;57(1):100-101.

18. Langley RL. A review of venomous animal bites and stings in pregnant patients. Wilderness Environ Med. 2004;15(3):207-215.

19. Mehmet D, Mehmet RH, Erdal P, et al. Reptile bite in pregnancy. Obstet Gynecol Surv. 2009;27(12):931-932.

20. Ngan Kee WD, Khaw KS. Vasopressors in obstetrics: what should we be using. Curr Opin Anaesthesiol. 2006;19:238-243.

21. Vijeth SR, Dutta TK, Shahapurkar J, et al. Dose and frequency of anti-snake venom injection in treatment of Echis carinatus (saw-scaled viper) bite. J Assoc Physicians India. 2000;48(2):187-191.

22. Snake Venom Antiserum IP. Toxinfo.org. India bharat snake venom antiserum_2015-01-21.

23. Christof Schaefer, Paul Peters WJ, Richard MK. Drugs during Pregnancy and Lactation: Treatment Options and Risk Assessment. 1st ed. USA; 2011. 555p.

24. Biranchni NM, Mohanty CBK, Cuttack. Guidelines for Anti Snake Venom Therapy. 2010

25. Michael AB, George RS, Michael RF, et al. Critical Care Obstetrics. 5th ed. USA; 2010. 760p 